\title{
Editorial
}

\section{The Journal of Applied Oral Science will start the publication of online ahead of print articles in SciELO, MEDLINE and ISI Web of Knowledge}

Dear Readers,

As of May 2011, the Journal of Applied Oral Science (JAOS) will start publishing online ahead of print articles. As usual, files will be sent to SciELO, which will first publish them at http://www.scielo.br/jaos and then forward them for indexation in MEDLINE/PubMed and ISI Web of Knowledge.

This strategy will certainly benefit all the contributors who have their articles accepted for publication in the JAOS. Online ahead of print articles also have the Digital Object Identifier (DOI $®$ ), and can be tracked as well as cited. Such articles will eventually receive page numbers in a regular print issue of our journal, and the aforementioned databases will be timely and properly updated.

We hope this policy helps our contributors to have their works read and cited even before their final publication, in a dynamic way good science should be spread.

This achievement was always aimed by the JAOS. We apologize it took longer than we initially expected. We thank all of you for your patience, support and comprehension.

With our best regards,

\section{Carlos F. Santos}

DDS, MSc, PhD, Associate Professor

Editor-in-Chief

Journal of Applied Oral Science 